UCRL-ID-121228

\title{
Preliminary Report on the Implications of Mining Practices in an Open-Pit Gold Mine for Monitoring of a Comprehensive Test Ban Treaty
}

\author{
S. P. Jarpe \\ P. Goldstein \\ B. Moran \\ L. A. Glenn
}

This paper is submitted as

CTBT Seismic Research FY95 Deliverable No. 10 (S7.2.2)

July 1995

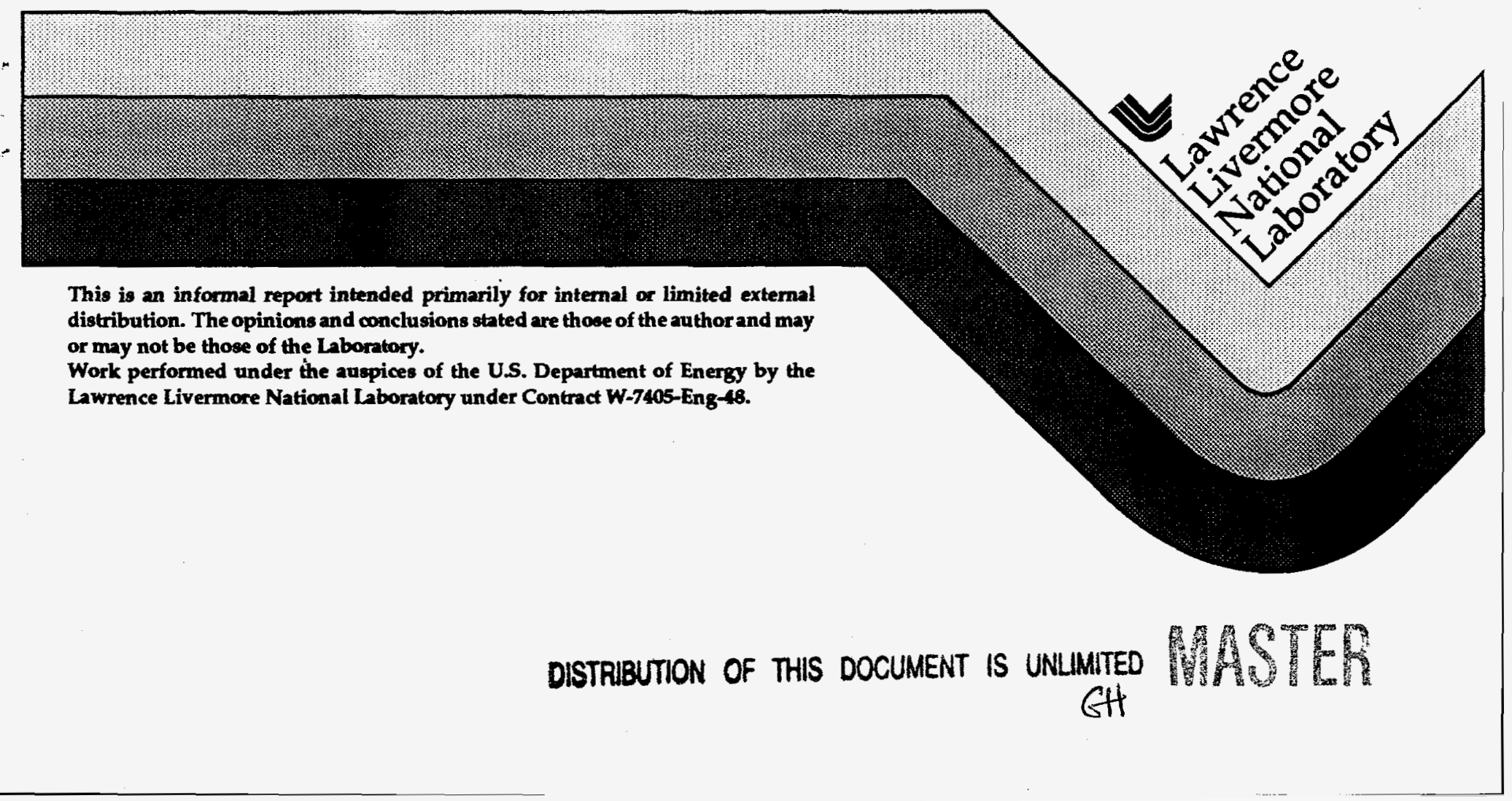




\section{DISCLAIMER}

This report was prepared as an account of work sponsored by an agency of the United States Government. Neither the United States Government nor any agency thereof, nor any of their employees, make any warranty, express or implied, or assumes any legal liability or responsibility for the accuracy, completeness, or usefulness of any information, apparatus, product, or process disclosed, or represents that its use would not infringe privately owned rights. Reference herein to any specific commercial product, process, or service by trade name, trademark, manufacturer, or otherwise does not necessarily constitute or imply its endorsement, recommendation, or favoring by the United States Government or any agency thereof. The views and opinions of authors expressed herein do not necessarily state or reflect those of the United States Government or any agency thereof. 


\section{DISCLAIMER}

Portions of this document may be illegible in electronic image products. Images are produced from the best available original document. 


\title{
PRELIMINARY REPORT
}

\section{Implications of Mining Practices in an Open-Pit Gold Mine for Monitoring of a Comprehensive Test-Ban Treaty}

\author{
S. P. Jarpe, P. Goldstein, B. Moran and L. A. Glenn
}

\begin{abstract}
This report summarizes the preliminary results of an ongoing experiment at the Gold Quarry pit, operated by the Newmont Gold Company at Carlin. NV. The purpose of the experiment is to obtain local and regional seismic data, together with "ground truth", from conventional surface blasting activity and to use these data to help determine the effectiveness with which conventional mining blasts can be discriminated from underground nuclear explosions.
\end{abstract}

\section{Introduction}

It is well known that chemical explosions can appear on seismic records as nuclear explosions under the right conditions. It is obviously important, in monitoring a comprehensive test ban treaty (CTBT), to be able to distinguish one from the other since mines throughout the world routinely employ chemical explosives in large quantities. In conventional mining practice, large-scale explosions are normally conducted in what is known as ripple-fired mode. With this technique, an array of holes is drilled, filled with explosive, tamped, and then fired in a spatial and temporal sequence designed to obtain maximum efficiency in rock comminution while, at the same time, reducing to a minimum ground motions in areas proximal to the mine and material thrown into the air. It is easy to show that the seismic signature from this kind of explosion can, in principle at least, be distinguished from that produced by a concentrated charge. In the former case, and for simple shot patterns and delays, a regular, time-independent spectral modulation is predicted in the coda, where the characteristic frequency is inversely proportional to the programmed delay. Spectral modulation has been observed by several investigators [Stump and Reamer (1988), Smith (1989), Hedlin et al. (1989, 1990), Chapman et al. (1992), Kim et al. (1994)]. When the shot patterns are not simple and the delays sufficiently irregular, however, the spectral modulation may diminish or disappear altogether.

As suggested by the conventional practice, ripple firing also is predicted to reduce the amplitude of the seismic signal by up to several orders of magnitude. It has been argued [Richards (1994)] that the great majority of mining blasts are unlikely to be confused for underground nuclear explosions because only about 10 to 30 chemical explosions per year in the U.S. are detected teleseismically with magnitudes greater than 3.0 (and, by extension, the number worldwide would presumably not be significantly greater). However, clandestine nuclear explosions 
would likely be carried out in large cavities; assuming, conservatively, that a decoupling factor of 50 is achieved in such a cavity, a kiloton nuclear explosion would produce an $m_{b}$ of 2.1 (based on the scale developed by Vergino and Mensing [1990] for the Nevada Test Site). Clearly, a very large number of mines worldwide perform explosions at this level. Hence, even the verification of a kiloton threshold would require discriminating between many mine explosions each day and the (hopefully) occasional attempt at evasion.

To shed more light on the effects of mining practices on the monitoring of a CTBT, the LLNL Treaty Verification Program is conducting an investigation of surface mining blasts in metamorphic rock in the Carlin, NV area. This study is part of a larger effort that includes a joint experiment with LANL at a large coal mine in Wyoming, the monitoring of a "first cave" in an underground coal mine in Colorado, and cavity decoupling experiments at the Nevada Test Site and in a mine in New Mexico. The main objectives of the Carlin investigation are:

- Assess the effectiveness of methods to identify ripple-fired explosions based on time-independent spectral modulation and determine under what explosive firing conditions these methods are not effective.

- Identify explosion firing conditions that produce seismic signals that appear to be concentrated explosions and determine the relative frequency of these events.

- Determine the relationship between the seismic magnitudes of mining explosions and explosion parameters such as total yield and firing parameters.

In what follows we give details on the field deployment, discuss the parameters involved in the experiments, describe the data obtained thus far, the methods used for data processing, and the results of our preliminary analysis. The final report of this study will follow the same format, but will be inclusive of all the data obtained and will attempt to summarize the results in terms useful for policy decisions.

\section{Newmont Gold Company Deployment}

We are working with the Newmont Gold Company (NGC), which operates an extensive open-pit gold mining operation in the Carlin, NV area. Their largest pit is the Gold Quarry, in which they conduct 2-325-to 150-ton explosions each week. Our deployment, which began April 11,1995 and will last approximately 4 months, consists of 7 portable seismic recorders in addition to the LLNL permanent network ELK station, which is $80 \mathrm{~km}$ from Gold Quarry. Four of the stations are within $2 \mathrm{~km}$ of Gold Quarry, two are $20 \mathrm{~km}$ northwest and southeast, and one is $50 \mathrm{~km}$ to the northwest. (see Figure 1.) Figures $2 \mathrm{a}$-d show photographs of the NGC operations and the LLNL deployment.

We are obtaining detailed information about the mining blasts from the NGC. This information includes shot geometry, amount of explosive in each hole, and delay times between shot holes. The close-in seismic stations allow us to positively identify the times and locations of the 


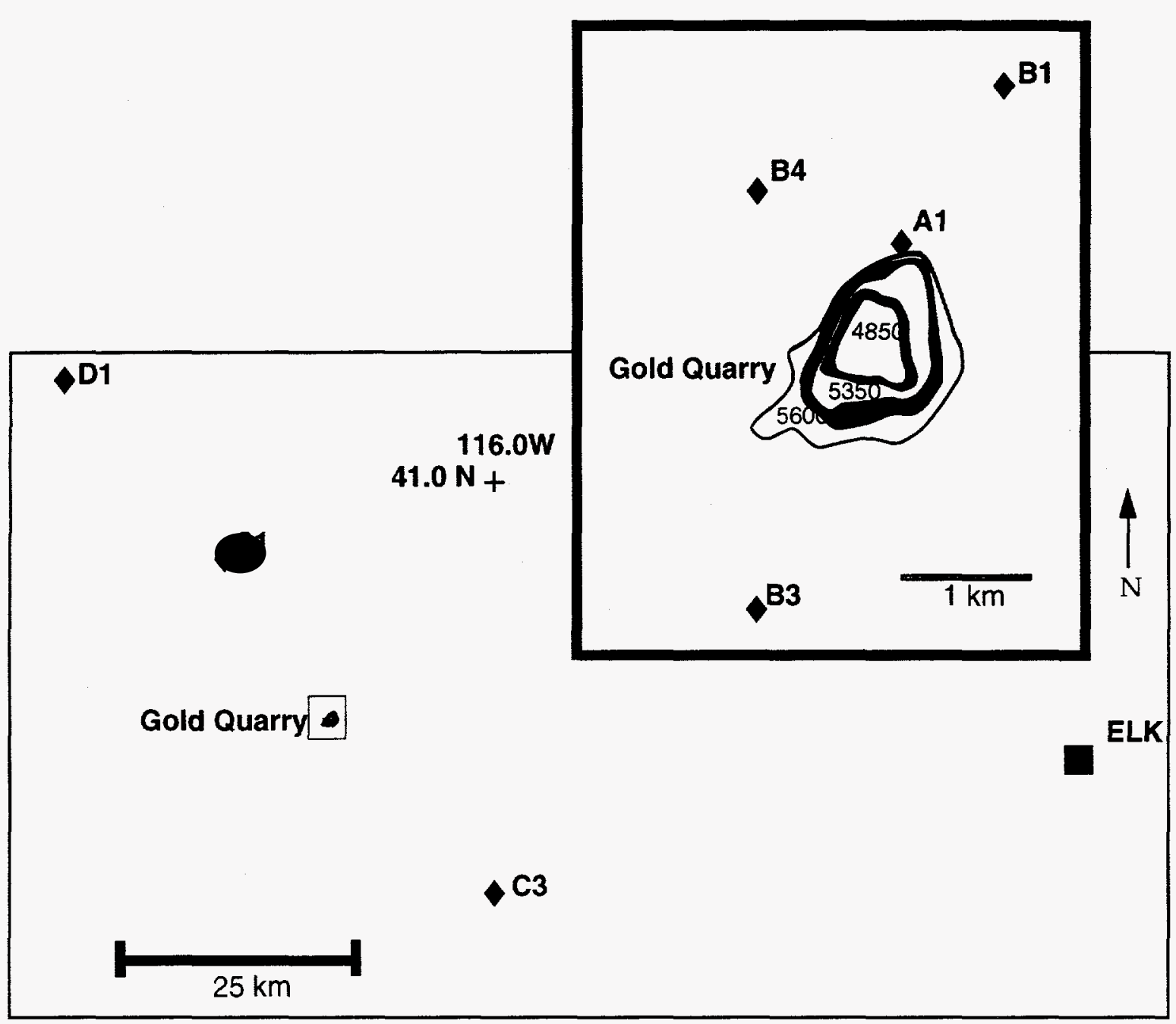

Figure 1. Location map. The diamond symbols are the locations of the temporary seismic recording sites, and the square shows the location of the LLNL permanent station, ELK. The inset (location shown by box on base map) shows the Gold Quarry area in detail. The unshaded regions are the main working levels in the Gold Quarry pit, which are at the 4850,5350 , and 5600 foot elevations (above sea level).

mining blasts. Once the shots are identified, we can compare the seismic signals recorded at greater distances $(50-100 \mathrm{~km})$ with the results of simulations of the shots derived from the "ground truth", which is the detailed information from the blasting logs.

\section{Parameters Involved in the Experiments}

The Newmont Gold Co. provided blasting logs for all shots that they conducted during our deployment period. These logs consisted of diagrams of the shot hole positions and the order in which the holes were fired, the average amount of explosive in each hole, and the delays between each group of shots. Figure 3 is a sample of the information provided for one shot; some of this information is summarized for 11 NGC shots in Table 1.

The blasting logs did not provide the exact time of each shot, so we used our close-in seismic 


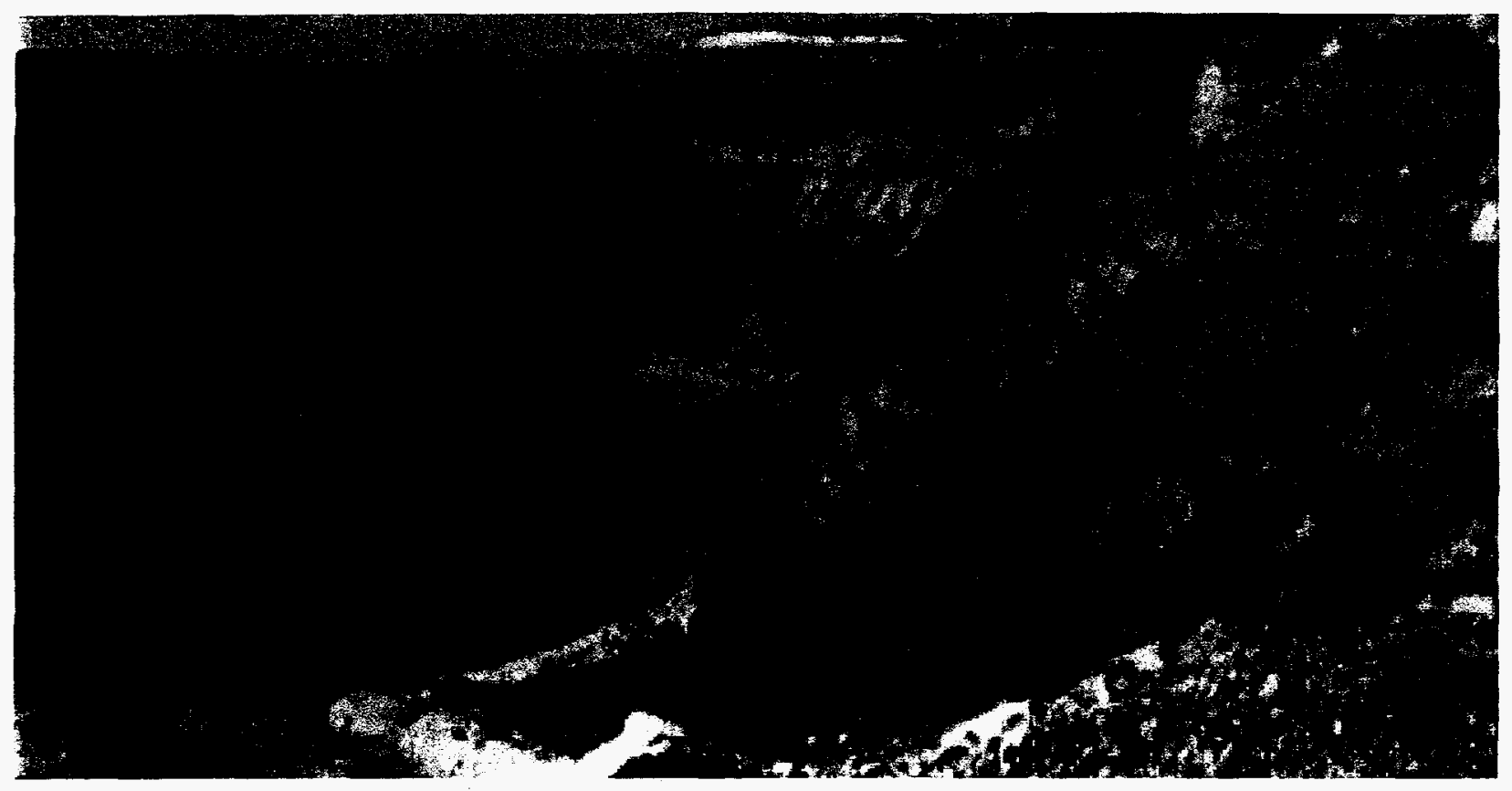

Figure 2a. Partial view of the Newmont Gold Company's Gold Quarry. The pit is approximately 1.5 kilometers in diameter and 250 meters deep.

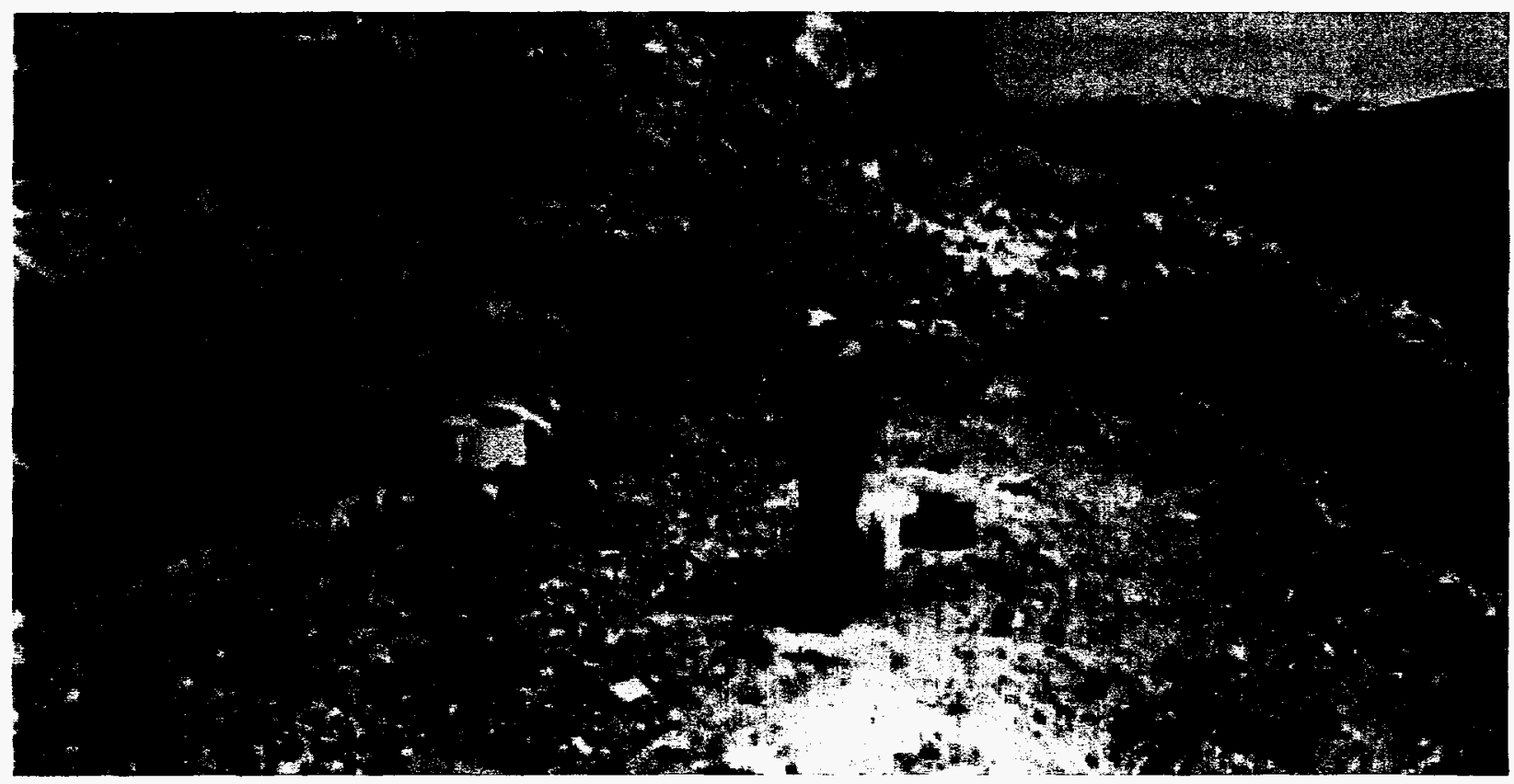

Figure $\mathbf{2 b}$. Installation of the LLNL seismic recording equipment at site D4. The white PVC pipe houses the sensor, which is installed on a cement pad, and the white box contains the recording system. The recording system consists of a Refraction Technology $72 \mathrm{~A}$ data acquisition unit and a 1000 megabyte hard drive. The seismic system is powered by a 12 -volt battery charged by a solar panel. 


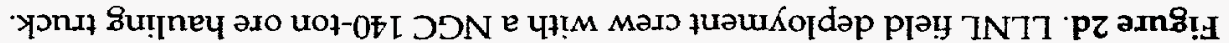

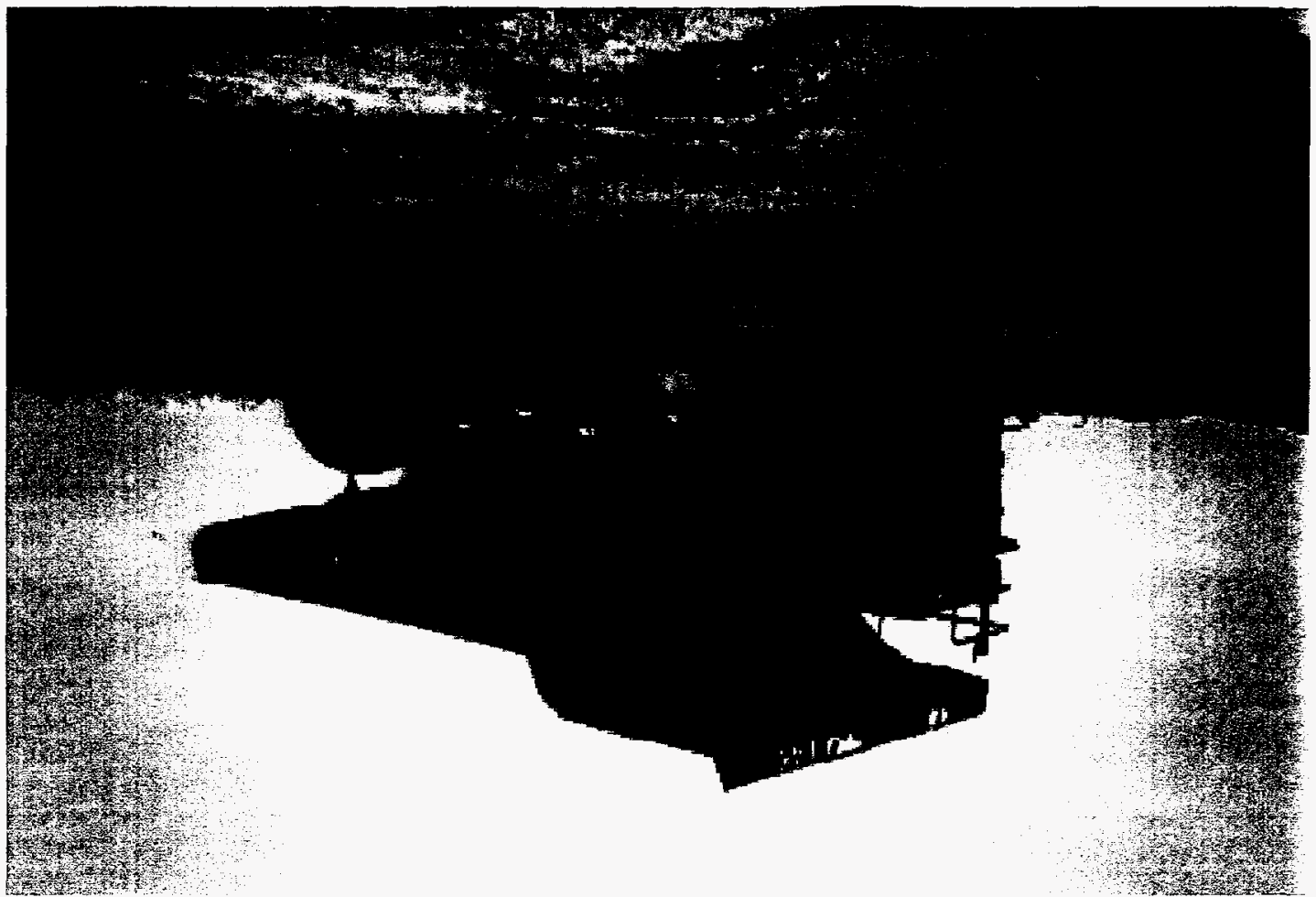

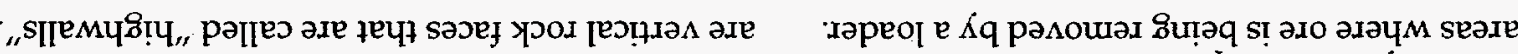

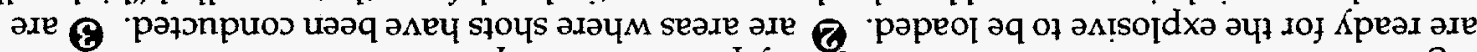

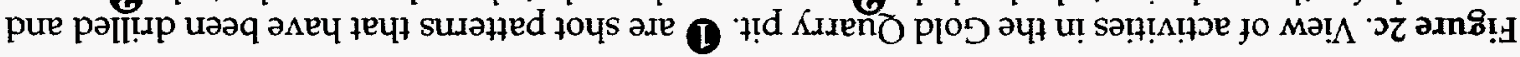

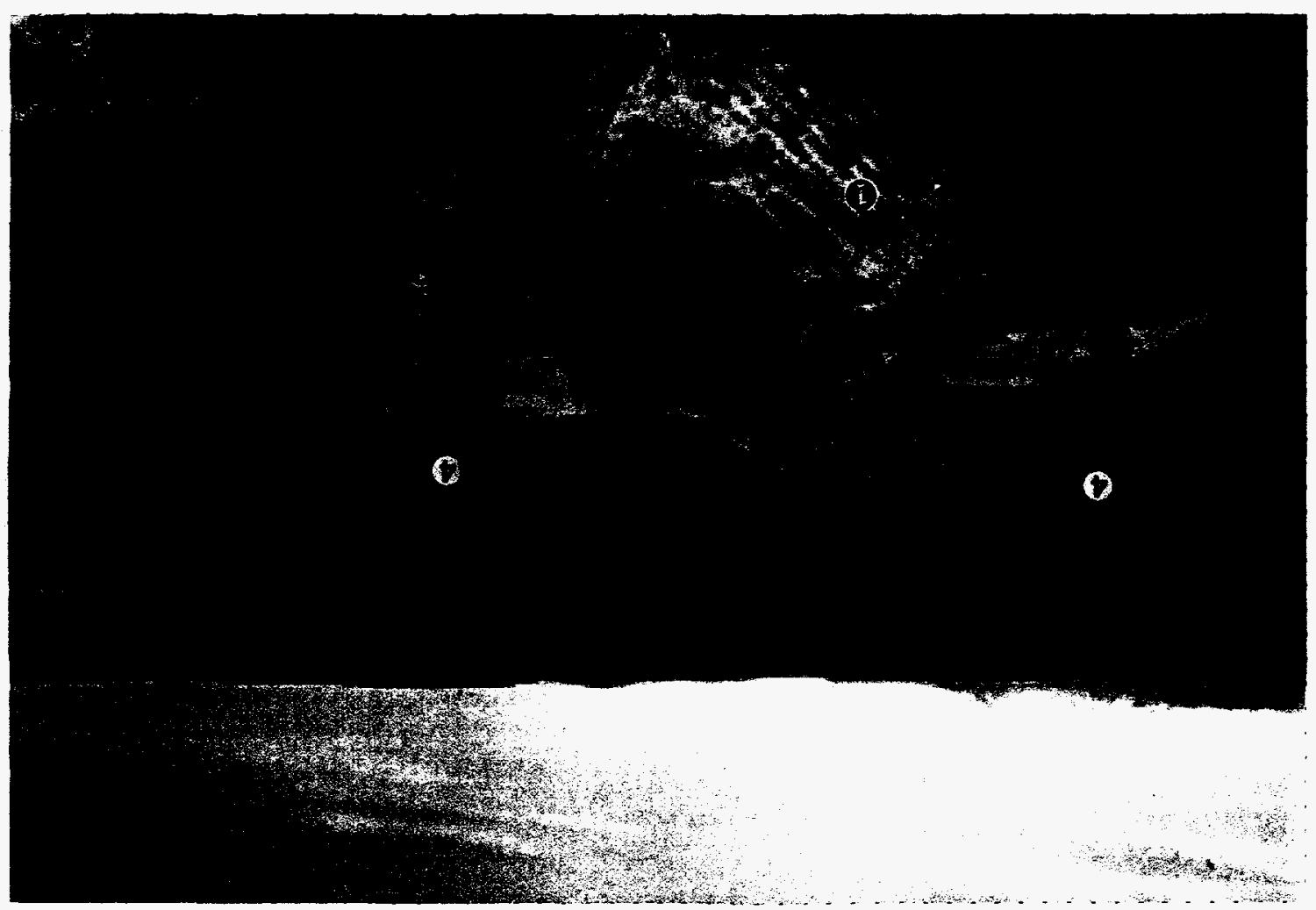




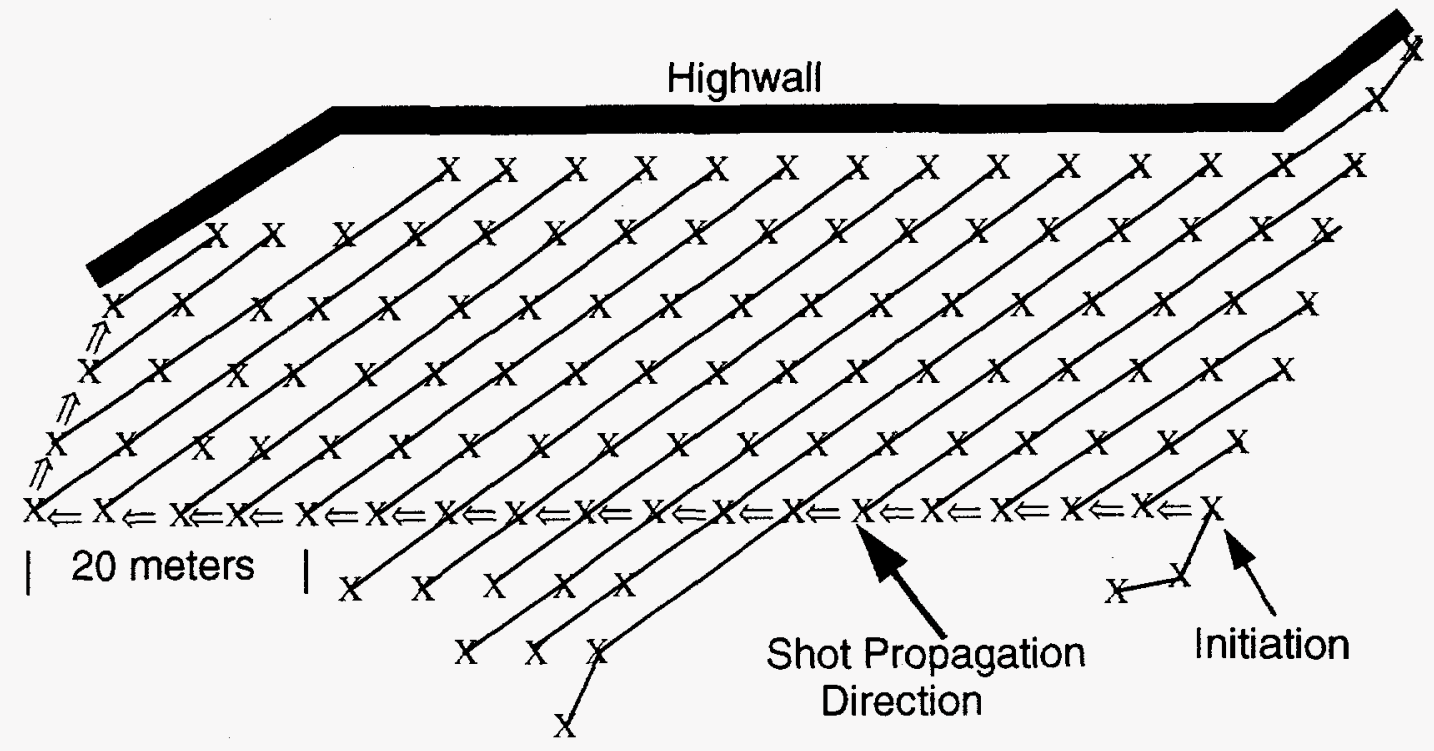

Figure 3. Sample plan-view shot pattern diagram for the Newmont explosion 0420_1 (see Table 1). The Xsymbols are the locations of the individual shot holes, and the solid lines show how the holes in an individual shot delay (group of shots fired simultaneously) are tied together by detonating cord. The small double-arrows represent the delays ( 65 milliseconds for this shot) between groups of shots. The highwall is the vertical face rising upward from the horizontal bench in which the shot is fired, and the remaining perimeter is a vertical surface 7.5 meters high extending downward from the bench surface.

Table 1: Parameters of NGC shots referred to in this report.

\begin{tabular}{|l|l|l|l|l|}
\hline LLNL_ID & delay $(\mathrm{ms})$ & \#holes & lbs/hole & \#delays \\
\hline 0413 & 50 & 802 & 290 & 34 \\
\hline $0414 \_1$ & 100 & 409 & 270 & 40 \\
\hline $0414 \_2$ & 35 & 120 & 204 & 14 \\
\hline 0418 & 50 & 515 & 280 & 37 \\
\hline $0420 \_1$ & 65 & 115 & 280 & 21 \\
\hline $0420 \_2$ & 65 & 939 & 270 & 158 \\
\hline 0427 & 100 & 872 & 275 & 87 \\
\hline $0505 \_1$ & 65 & 250 & 295 & 25 \\
\hline $0505 \_2$ & 65 & 242 & 220 & 12 \\
\hline $0509 \_1$ & 65 & 160 & 280 & 19 \\
\hline $0509 \_2$ & 100 & 420 & 280 & 62 \\
\hline
\end{tabular}




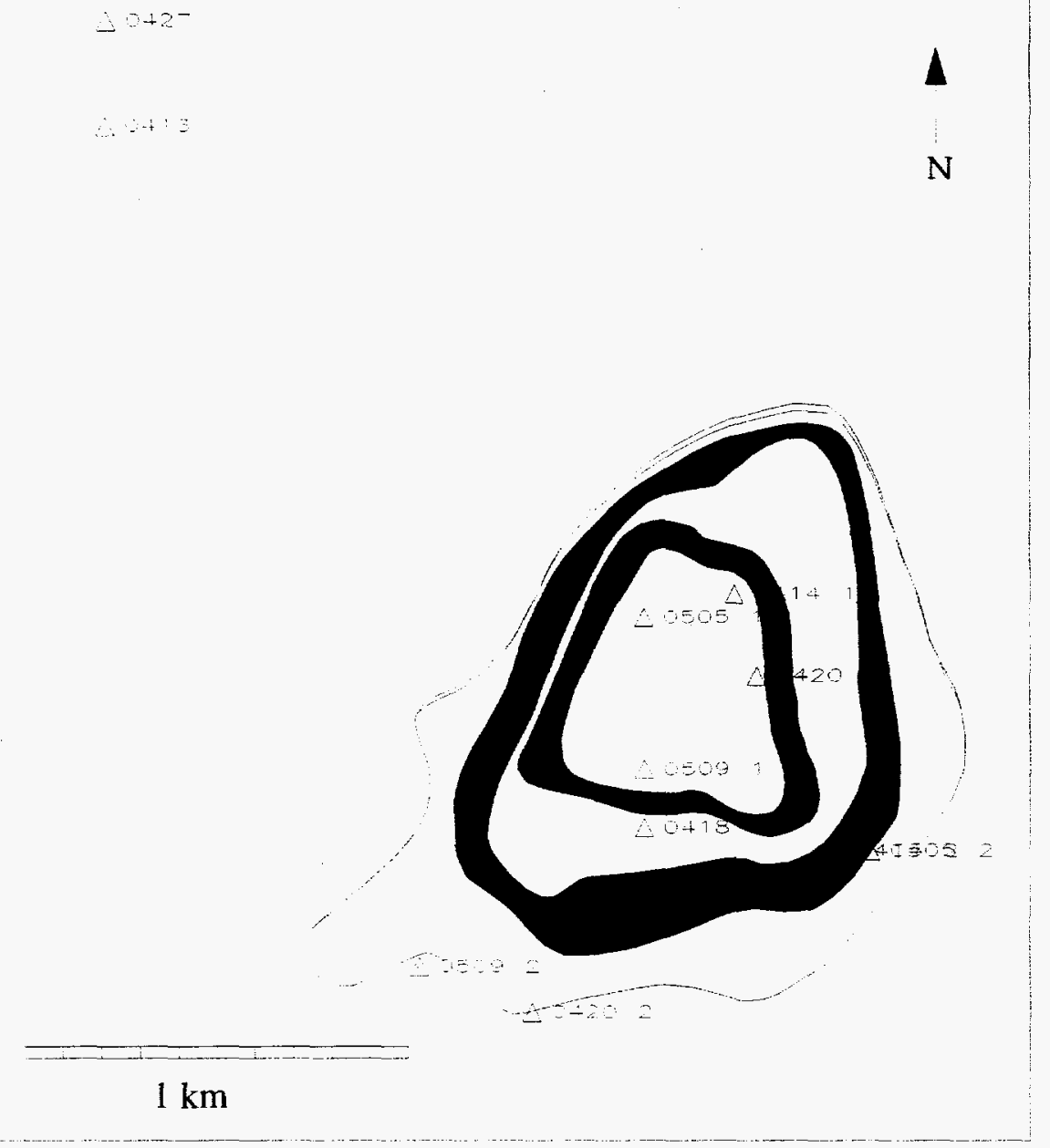

Figure 4. Map of NGC shots in Table 1. The major features of the Gold Quarry are shown as in Figure 1. The two shots to the northwest are in the "Tusc" pit.

stations to determine the times. The Newmont blasters frequently fire more than one shot at a time. The individual shots are from 5 seconds to several minutes apart. Shots fired less than 30 seconds apart do not appear as separate signals at distances greater than about $50 \mathrm{~km}$.

Table 1 shows the shot parameters for Newmont explosions that we were able to unambiguously correlate with the seismic signals. Figure 4 shows the locations of those shots in the pit.

\section{Evidence of Ripple Firing}

As noted above, the observation of time independent spectral modulations is a very good indication that an event involved ripple firing. Time independent spectral modulation is usually identified by looking for continuous peaks in plots of spectral amplitude, or some closely related measurement. as a function of time (e.g., Hedlin et al. [1989]; Wuster [1993]). We use high-resolution spectrograms and binary sonograms (e.g., Figure 5) to identify events with time-independent spectral modulation. Our spectrograms consist of a time-sequence of high-resolution spectral amplitude estimates. Each estimate is obtained by windowing a two-second segment of data, 

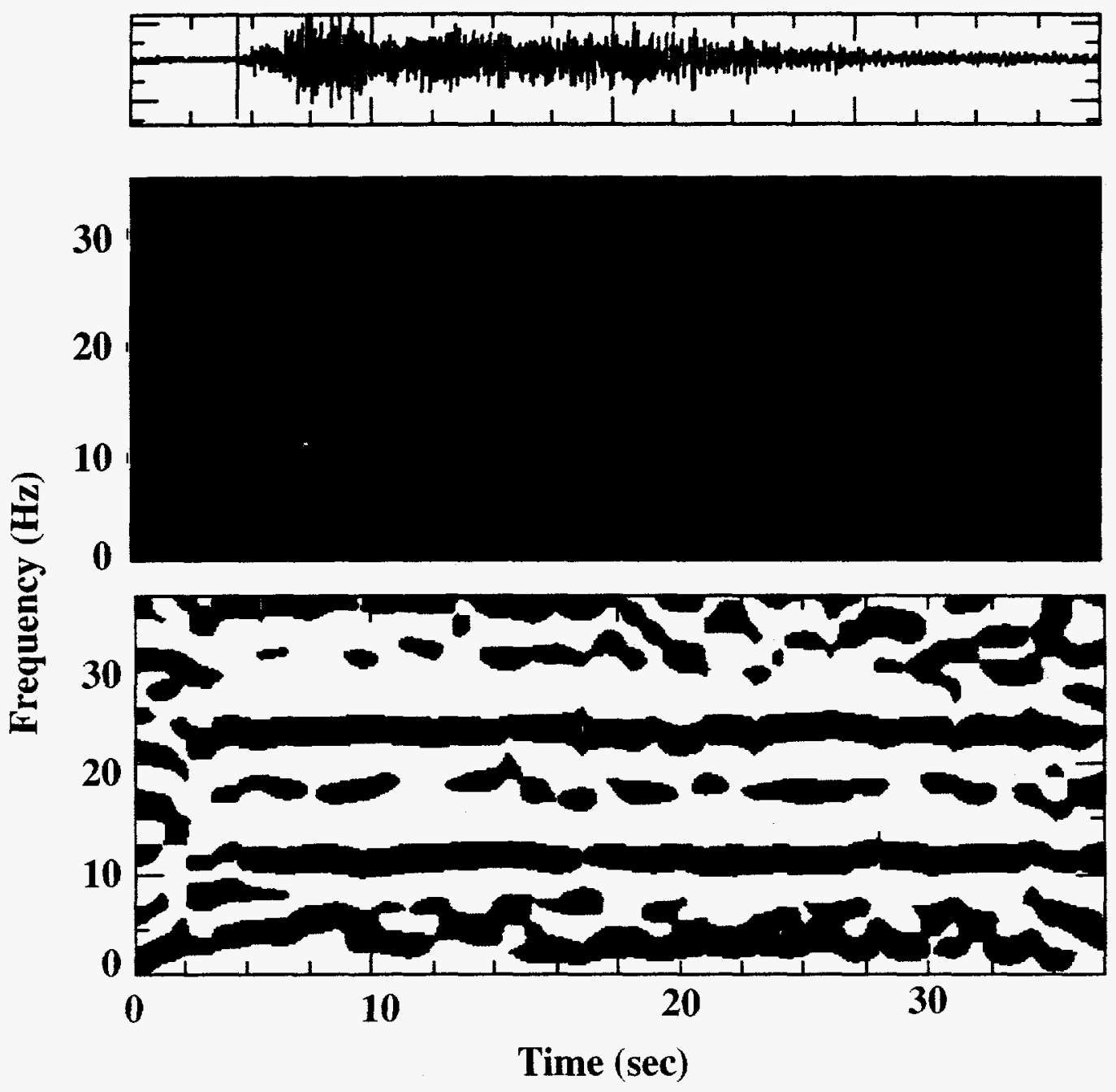

Figure 5. Time series (acceleration), spectrogram, and binary sonogram for event 0420_1 recorded at ELK.

tapering with a 5\% hamming taper, computing the data autocorrelation function, and computing a maximum entropy or maximum likelihood power spectral estimate. There is one second of overlap between successive windows. We compute binary sonograms by taking the difference between a spectrogram that has been smoothed over a $10 \mathrm{~Hz}$ bandwidth and the unsmoothed spectrogram, and setting all the resulting negative values to zero and all positive values to one. Color spectrograms are obtained by converting the spectral amplitudes to integers between zero and 255 and assigning a color to all 256 integers. Black and white sonograms are obtained by assigning all points with the value of one to black and all points with the value of zero to white. Time-independent spectral modulation is represented by continuous horizontal bands in the color spectrograms and black and white sonograms, that are not present in the pre-event noise.

In Figures 6 and 7 we compare spectrograms and sonograms of 10 events that were recorded during the first month of our deployment. Careful inspection of these images indicates that most of the events exhibit clear evidence of time-independent spectral modulation. However, two 

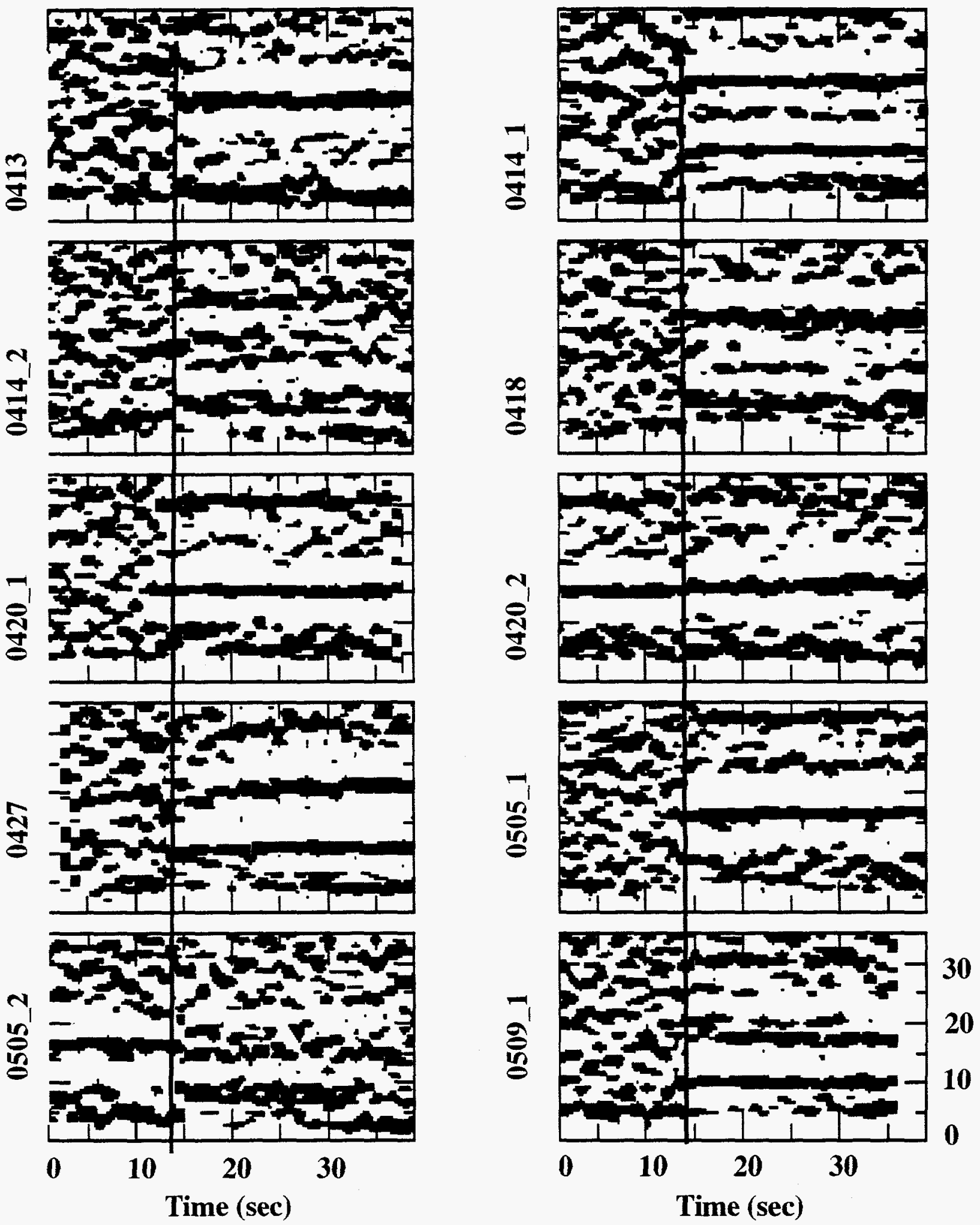

Figure 6. Binary sonograms for 10 of the shots described in Table 1, calculated from seismograms recorded at ELK, $80 \mathrm{~km}$ distance. The horizontal axis is time (sec) and the vertical axis is frequency $(\mathrm{Hz})$. The vertical lines represent the beginning of the $\mathrm{P}$-wave data, the time before that is pre-arrival noise. The pre-event noise of shots 0420_2 and 0505_2 have interference from the coda of previous shots. 

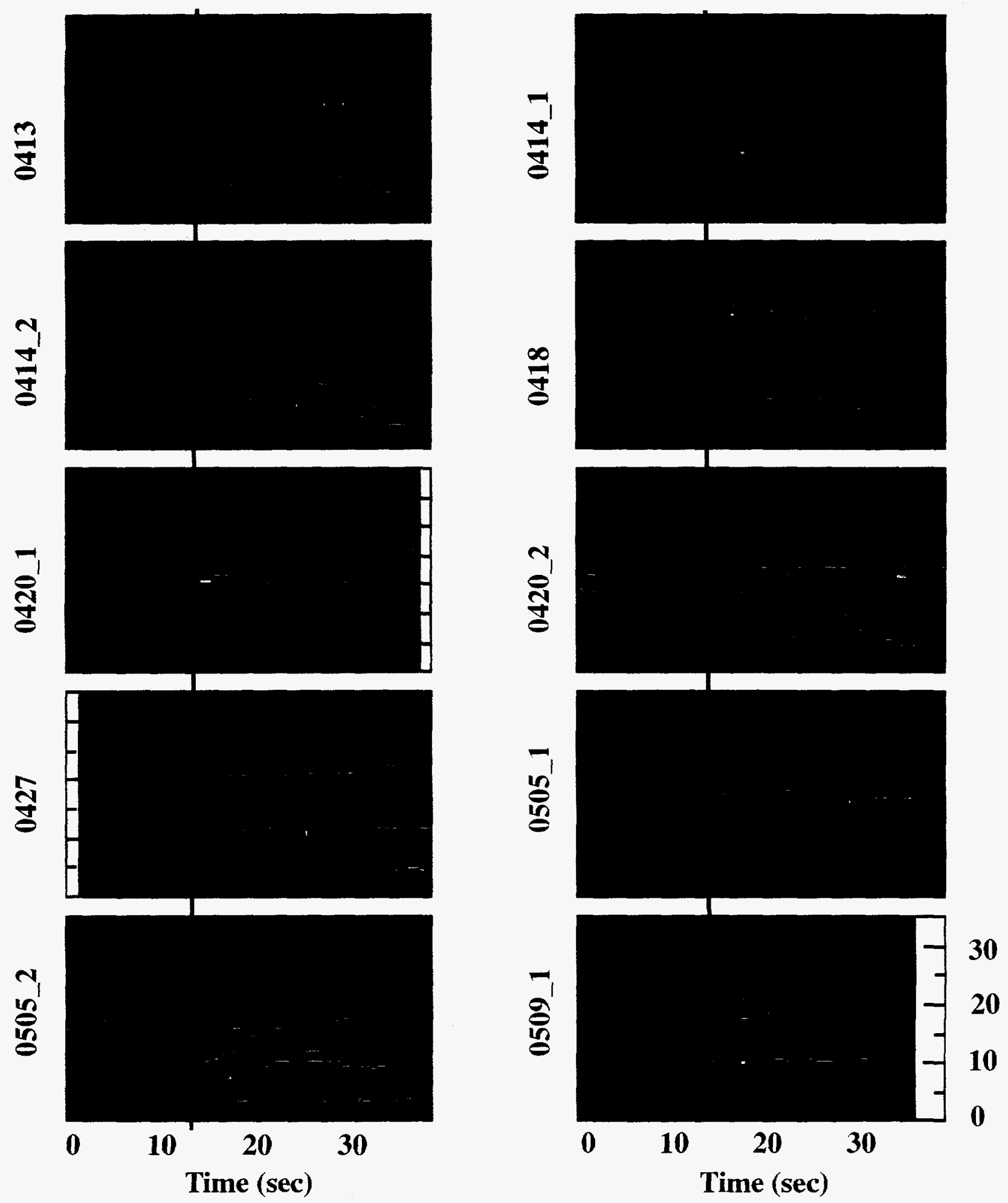

Figure 7. Spectrograms for 10 of the shots described in Table 1, calculated from seismograms recorded at ELK, $80 \mathrm{~km}$ distance. The horizontal axis is time $(\mathrm{sec})$, and the vertical axis is frequency $(\mathrm{Hz})$. The vertical lines represent the beginning of the P-wave data, the time before that is pre-arrival noise. The pre-event noise of shots $0420 \_2$ and $0505 \_2$ have interference from the coda of previous shots. 
events do not show clear horizontal banding. One of these, labeled 0414_2, may have some banding that is difficult to distinguish from the noise. There are no indications of banding in the spectrogram or sonogram of the event labeled 0505_2.

Both explosions lacking spectral modulation fall into a special class of ripple-fired explosions referred to by mining company personnel as "waste-shots". These shots usually involved a relatively small number of rows of charges, had relatively small total explosive yield, and were designed to break-up rock that was covering up the ore-grade material.

We have been testing a variety of hypotheses to see if they can explain the presence or lack of spectral modulation in the observed spectograms. For example, we considered the possibility that attenuation, or directional propagation of the explosions could account for the lack of modulation in the waste shots. If attenuation were responsible, we would expect spectral peaking to occur in data recorded close to the explosion, and gradually disappear as we move further away. Based on a lack of consistent spectral peaking in recordings at a variety of azimuths and distances of approximately 2,25 and $80 \mathrm{~km}$, neither attenuation nor directional propagation appear to account for the lack of modulation.

We have also been comparing the observed spectral modulation with predictions from numerical models. As a first approximation, we expect to see modulation at frequencies that are inversely proportional to the nominal delay times between rows of charges. The observations are in general agreement with this simple model. Figure 8 compares the observed and calculated frequencies of spectral peaking for 7 Gold Quarry explosions for which the peaking was clearly observed. The circles with crosses are the primary spectral peaks and the open circles are the secondary peaks (harmonics). The calculated primary frequency is the reciprocal of the delay between rows provided by the blasting logs and the secondary frequencies are double the primary frequencies. The observed frequencies are measured at the ELK station, approximately $80 \mathrm{~km}$ from the Gold Quarry. This plot shows that there is generally good agreement between observed and expected frequencies of spectral enhancement in the ripple-fired shots.

\section{Synthetic signals}

We used the ground truth information that has been collected so far to generate synthetic signals for two mining events. We chose a waste shot and a production shot, both fired on $4 / 14$, to demonstrate the qualitative difference between the two signals. We assumed that each charge in the blast will eventually form an elastic spherically symmetric shock front which can be approximated as if emanating from a spherical source driven by a step pressure function; the magnitude of the step pressure is proportional to the yield of the charge. This model is similar to the MuellerMurphy model (Mueller and Murphy [1971]) which has been shown to adequately represent the seismic signal from high explosives (Stump and Reinke [1988]). The assumption of a spherical shock front from an individual charge is also consistent with recent LANL field experiments in which spectral comparisons of ground motion data from fully burdened cylindrical and pseudospherical single shots showed no significant differences in compressional energy (Stump and Pearson [1995]). 


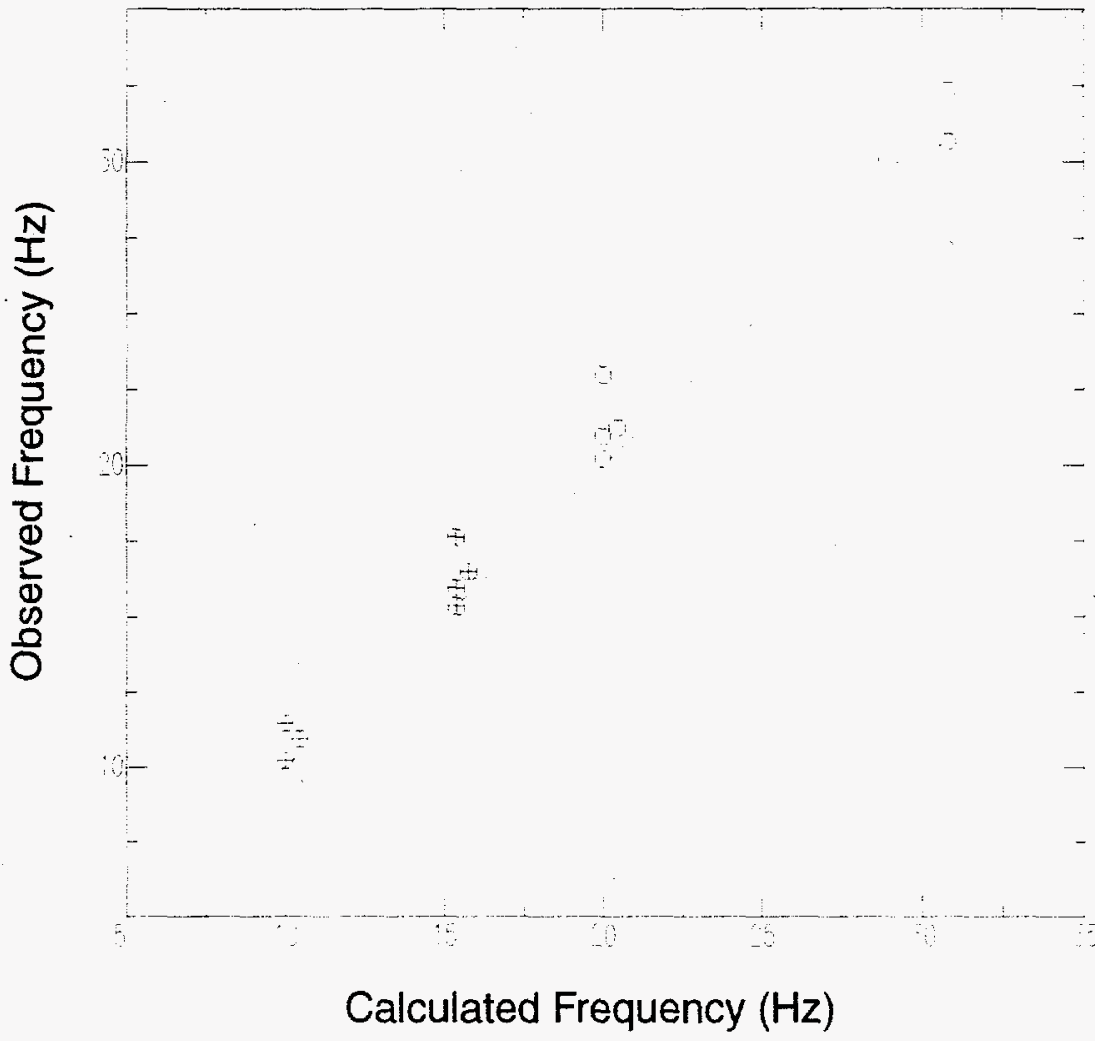

Figure 8. Comparison of the observed and calculated frequencies of spectral peaking for 7 Newmont explosions for which the peaking was clearly observed.

In our simulation we assumed linear superposition of the stress and displacement fields from each charge. To investigate this assumption, we carried out two- and three- dimensional hydrocode calculations of multiple charges separated by various distances. We found that, regardless of the number of charges and their spatial arrangement, the waveforms added nearly linearly as long as the separation between any two charges was at least $50 \mathrm{~m} / \mathrm{kt}^{1 / 3}$. This minimum separation varied with material properties, yet remained smaller than the elastic radius. When the minimum separation was much smaller than the elastic radius. the charges fused and linear superposition was no longer valid. This happened when the minimum separation was typically less than $10 \mathrm{~m} / \mathrm{kt}^{1 / 3}$. The separation between holes in the NGC explosions were typically $5 \mathrm{~m}$ and the charge per hole was about $0.00015 \mathrm{kt}$ resulting in a scaled separation of $94 \mathrm{~m} / \mathrm{kt}^{1 / 3}$, which is greater than $50 \mathrm{~m} / \mathrm{kt}^{1 / 3}$ thus justifying the use of linear superposition.

Figures 9 and 10 show the calculated synthetic amplitudes for the two shots fired on 4/14. The simulations accounted for the uncertainty in the delay times, due to manufacturing tolerances, by sampling from a normal distribution of delays. The synthetic production shot shows clear evidence of spectral modulation starting at $10 \mathrm{~Hz}$, with peaks well above the nominal amplitude at $1 \mathrm{~Hz}$. The modulations are at the expected frequencies and correspond to the reciprocal of the firing delays. By contrast, the waste shot, which had a shorter delay time ( $35 \mathrm{~ms}$ ) and fewer number of charges, shows no peaks with magnitude above the nominal amplitude at $1 \mathrm{~Hz}$. 


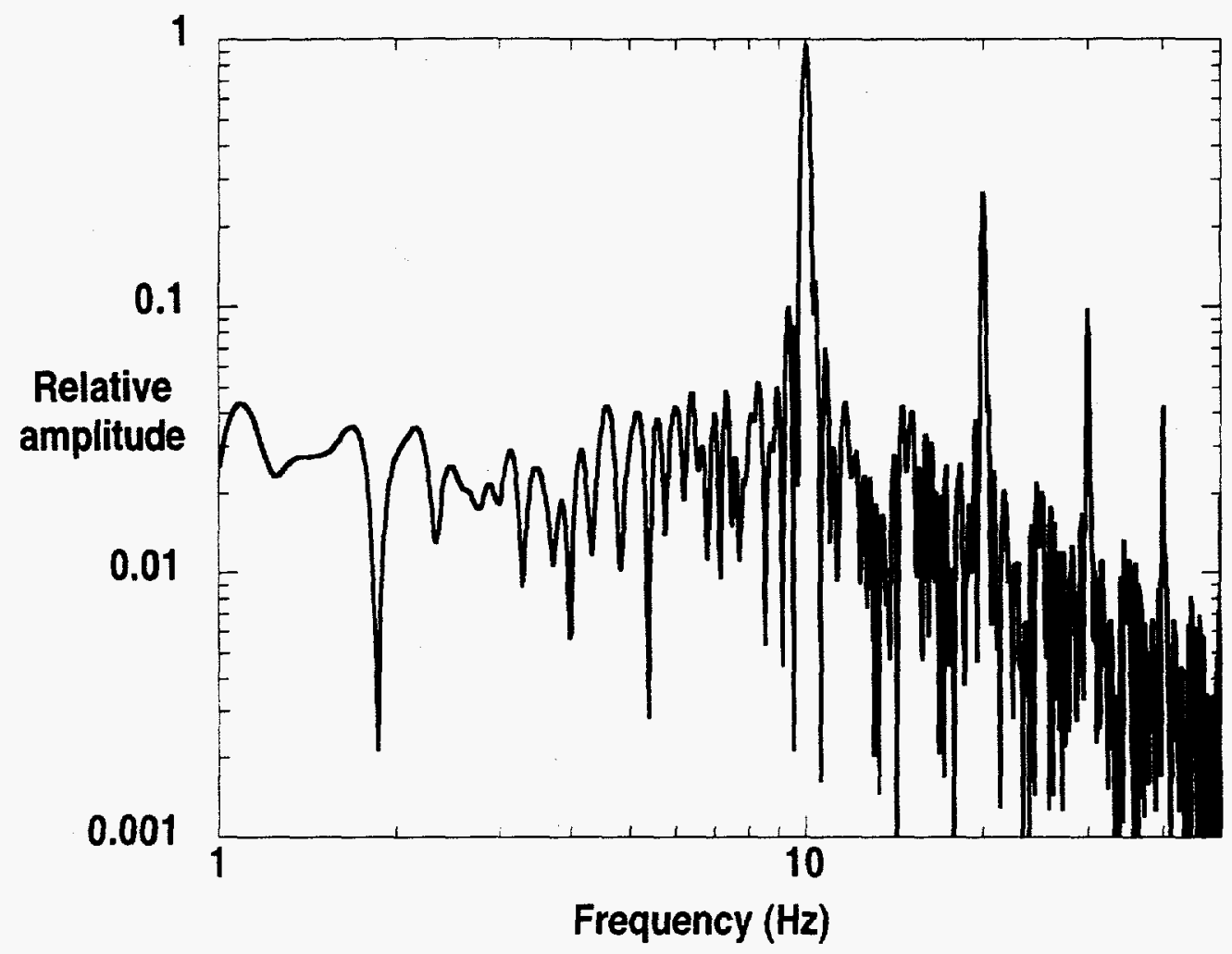

Figure 9. Synthetic amplitudes from the production shot 0414 _. The total number of holes was 409 and the total charge was $110,000 \mathrm{lbs}$ of ANFO. The nominal delay in this shot was $100 \mathrm{~ms}$. Note the peaks at 10,20,30,40, and $50 \mathrm{~ms}$.

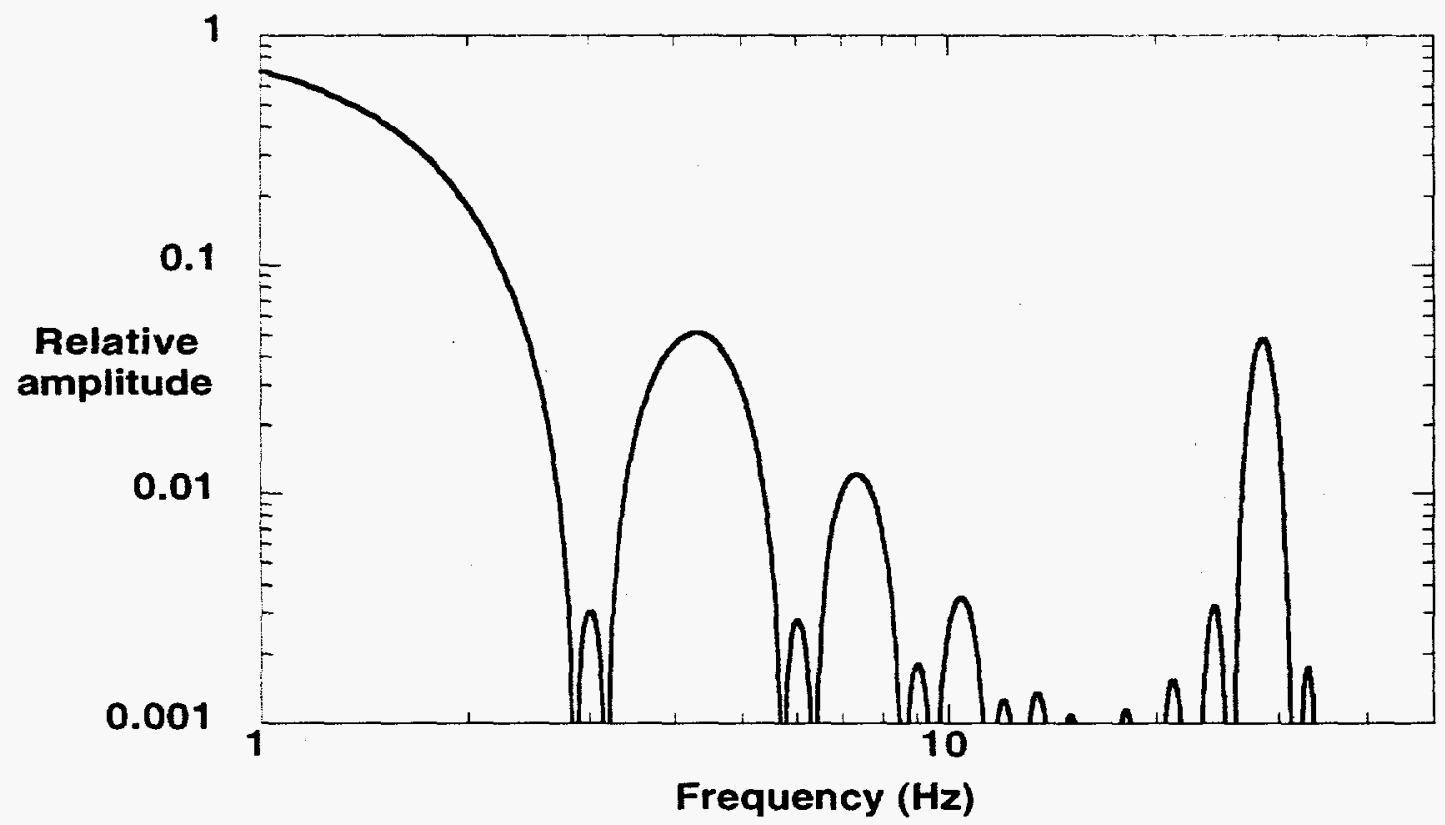

Figure 10. Synthetic amplitudes from the waste shot 0414_2. The total number of holes was 120 and the total charge was $24,000 \mathrm{lbs}$ of ANFO. The nominal delay in this shot was $35 \mathrm{~ms}$. Note that all the peaks are below the nominal amplitude at $1 \mathrm{~Hz}$ 


\section{Effect of shot parameters on magnitude}

The seismic magnitude for concentrated-charge explosions is well correlated with the logarithm of the yield. For ripple-fired explosions, the situation is much more complicated because the amplitude of the seismic signal is significantly modulated by destructive interference caused by the spatio-temporal firing pattern of the individual charges. The main question to be answered is: how does the magnitude of a ripple-fired explosion depend on the firing parameters? This question is of interest in understanding the behavior of ripple-fired explosions, but has relatively little significance from the point of view of nuclear monitoring since, even if a unique relationship were to be identified, the shot parameters are not likely to be known by the seismic monitor; hence the inversion of seismic amplitude for yield estimation could not be accomplished. For example, Figure 11 plots seismic magnitude as a function of total explosive yield for 9 of the first 11 events that we recorded at ELK in the current deployment at Carlin and for which a magnitude could be computed, as well as for 12 Newmont events that we recorded in September 1994. The magnitudes plotted were calculated from the explosion coda by the method developed by Mayeda [1993] and are normalized to the $p_{n}$ phase-magnitude determined for the Non-Proliferation Experiment (NPE). There appears to be no correlation between magnitude and total explosive yield in the figure; in fact, the larger yields seem to produce slightly lower magnitudes than do the smaller yields. Moreover, figure 11 shows that the correlation coefficient does not significantly increase when the magnitude is plotted against various other shot parameters, including yield per delay, number of delays, total shot duration, or the ratio of total explosive yield to total shot duration. (Note that in Figure 11 the yield is in kiloton-energy units; the specific energy of the ANFO blasting agent was taken as $3.636 \mathrm{~kJ} / \mathrm{g}$ )

It seems clear that the relationship between magnitude and shot parameters is more complex than can be represented by a simple, two-dimensional mapping. The two methods most likely to yield further information, nonlinear regression analysis and artificial neural networks, require substantially more data than are presently available. We expect to explore these approaches upon completion of the deployment, when we will have on the order of 50 events to study.

Although magnitude does not appear to be well correlated with any single shot parameter, figure 12 shows that it is consistent with the average relationship determined for the Nevada Test Site by Vergino and Mensing [1990]. In this figure the magnitude is plotted against the yield in kiloton-energy units and, as in figure 11, the data obtained in the first deployment are combined with the data from the explosions at Gold Quarry that were recorded in September 1994 (red color). Also shown in the figure are several events recorded at the Pinedale Seismic Research Facility from explosions in open-pit coal mines in the Powder River Basin in this same time frame (blue color). It is seen that virtually all the explosions exceed the amplitude of a hypothetical fully decoupled 1 kiloton explosion. Moreover, the 5 events identified as "waste shots" (plotted by the solid red symbols) exhibited no clearly identifiable spectral modulation at ELK and might therefore be misidentified as potential clandestine nuclear explosions in a verification scenario. 
(a)

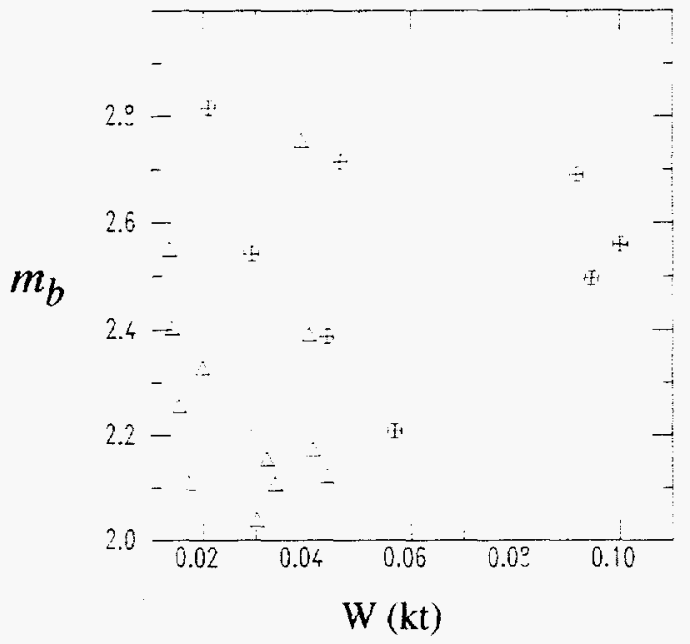

(c)

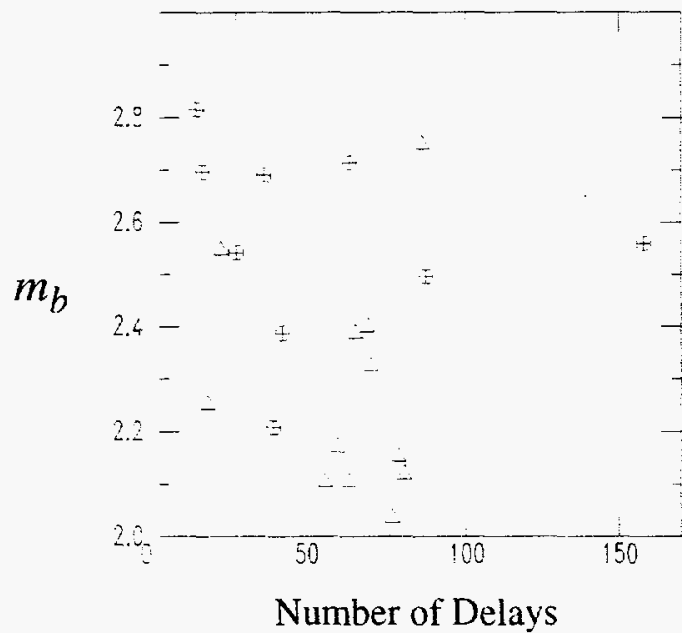

(b)

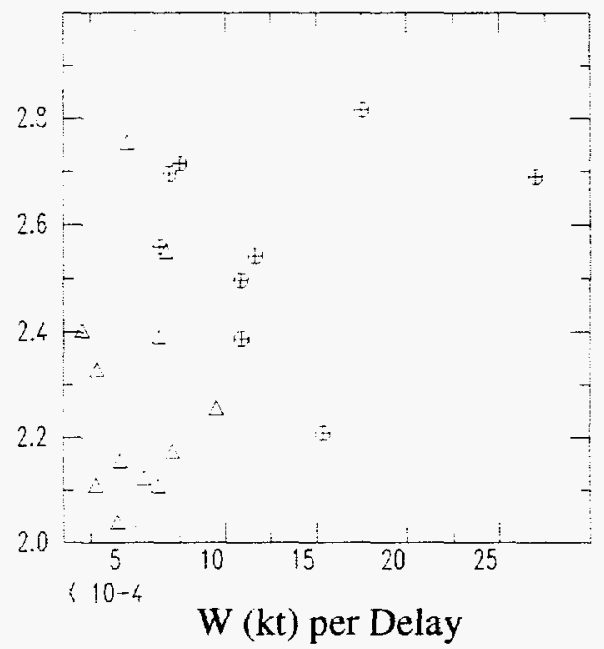

(d)

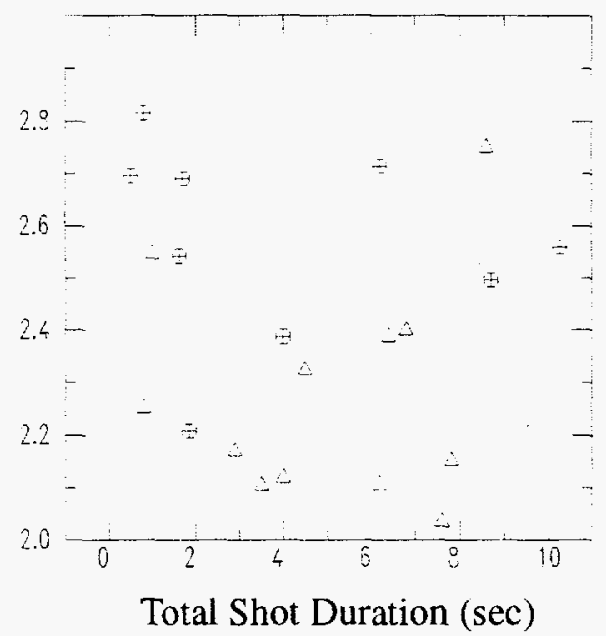

Figure 11. Magnitude at ELK as a function of (a) total yield, (b) yield per delay, (c) number of delays, and (d) total shot duration. The circular symbols are shots from the current study, and the triangular symbols are for shots from September, 1994.

\section{Summary and Concluding Remarks}

The LLNL Treaty Verification Program is conducting an ongoing investigation of surface mining blasts in metamorphic rock whose main objectives are to:

- Assess the effectiveness of methods to identify ripple-fired explosions, based on time-independent spectral modulation and determine under what blasting conditions these methods are ineffective.

- Identify explosion firing conditions that produce seismic signals that appear to be concentrated explosions and determine the relative frequency of these events.

- Determine the relationship between the seismic magnitudes of mining explosions and the size of the explosions, together with other parameters that control the magnitude. 


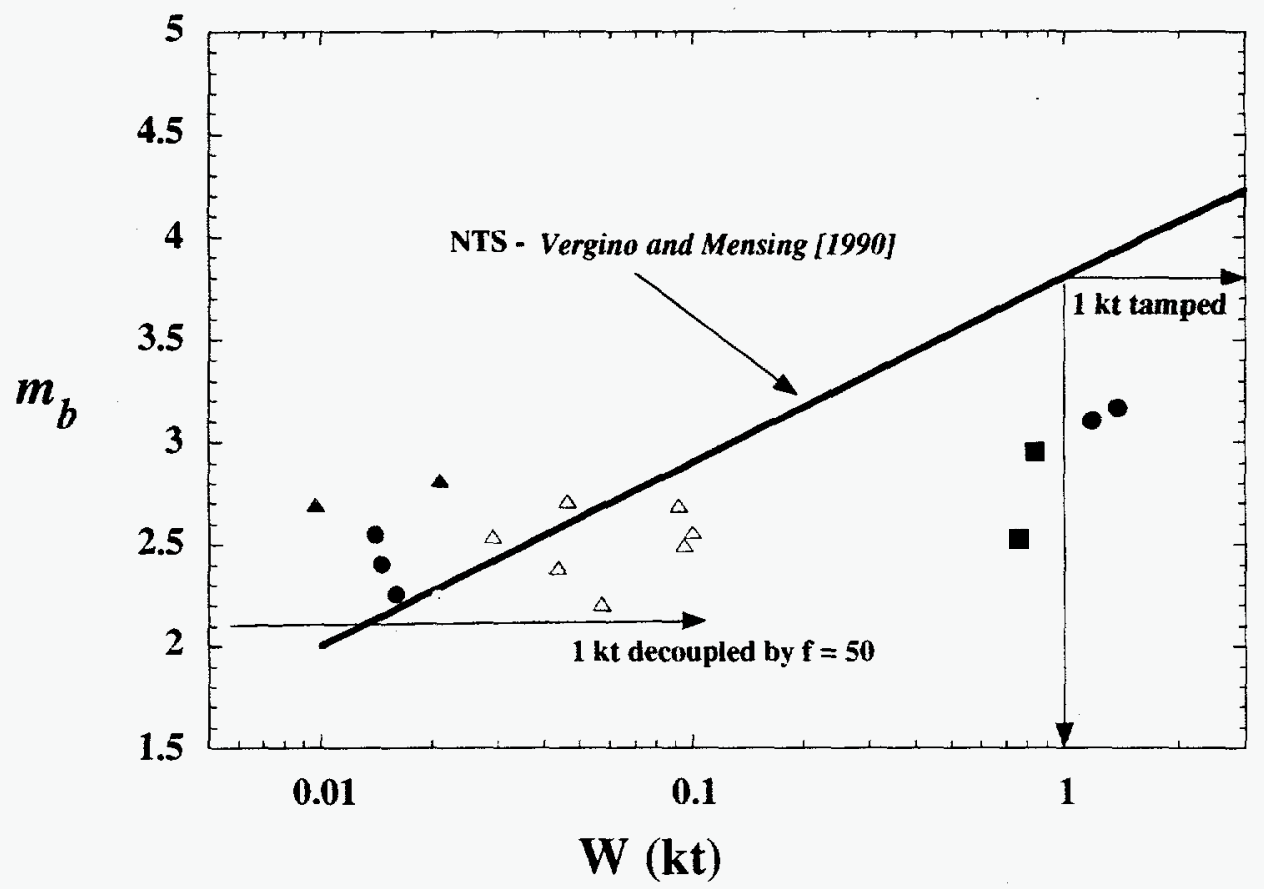

Figure 12. Magnitude as a function of total yield. The data in red were recorded at ELK from explosions at the Gold Quarry pit of the Newmont Gold Company in Carlin, NV. Open symbols represent shots for which spectral modulation was observed and closed symbols represent "waste shots" for which no modulation was observed. The circular symbols are for events recorded in September 1994 and the triangular symbols are for events recorded in the current deployment. The blue symbols represent explosions recorded at PSRF in 1994 from explosions in open-pit coal mines in the Powder River Basin; the circular symbols are from events at the Black Thunder Mine and the square symbols events at the Cordero Mine.

As of this writing, we have recorded approximately 30 events with complete "ground truth", and have performed preliminary analysis on 11 of these. Of the 11,9 have exhibited evidence of spectral modulation at a distance of $80 \mathrm{~km}$ (at ELK) and the frequency peaks are reasonably well correlated with the shot delays when the spatio-temporal firing pattern is simple. The other two events, called "waste shots" by the miners, did not exhibit spectral modulation. One of the waste shots (0414_2) was fired with $35 \mathrm{msec}$ delays, and the other (0505_1) with $65 \mathrm{msec}$ delays. Moreover, these shots had higher seismic magnitudes, as predicted by theory. While we have not yet accumulated sufficient statistics to state with confidence the relative frequency of occurrence of these waste shots, it appears as if they are not unusual. We are investigating possible reasons for their lack of spectral modulation and their higher than expected magnitudes; apart from the spatio-temporal firing parameters, other possible factors effecting the seismic response include material properties and water saturation of the firing medium. 


\section{Acknowledgments}

A special thanks is due the Newmont Gold Company (NGC) for their support and extended hospitality, and for their provision of ground truth data; we are grateful, in particular, to Jeff Mattern, Kurt Kriss, Trent Embry, and Ali Soltani. LLNL engineering and instrumentation support were provided by Don Rock, Pat Lewis, and Sierra Boyd. François Heuzé coordinated the arrangements for the deployment. This work was performed under the auspices of the U.S. Department of Energy by the Lawrence Livermore National Laboratory under contract No. W-7405-ENG-48. The DOE Program Manager in the Office of Research and Development (NN20) was Ms. Leslie A. Casey.

\section{References}

Chapman, M. C., G. A. Bollinger, and M. S. Sibol (1992). Modeling delay-fired explosion spectra at regional distances, Bull. Seism. Soc. Am. 82, 2430-2447.

.Hedlin, M. A. H., J. B. Minster, and J. A. Orcutt (1989). The time-frequency characteristics of quarry blasts and calibration explosions recorded in Kazakhstan, USSR, Geophys. J. Int. 99, 109-121.

Hedlin, M. A. H., J. B. Minster, and J. A. Orcutt (1990). An automatic means to discriminate between earthquakes and quarry blasts, Bull. Seism. Soc. Am. 80B, 2143-2160.

Kim, W. Y., D. W. Simpson, and P. G. Richards (1994) High-frequency spectra of regional phases from earthquakes and chemical explosions, Bull. Seism. Soc. Am. 84, 1365-1386.

Mayeda, K. (1993). mb(LgCoda): a stable single station estimator of magnitude, Bull. Seism. Soc. Am. 83, 851-861.

Richards, P. G. (1994). Blasting activity of the mining industry in the United States, in Symposium on the Non-Proliferation Experiment: Results and Implications for Test Ban Treaties, M. D. Denny (editor), Lawrence Livermore National Laboratory publication CONF-9404100, 2-16.

Smith, A. T. (1989). High-frequency seismic observations and models of chemical explosions: implications for the discrimination of ripple-fired mining blasts, Bull. Seism. Soc. Am. 79, 1089-1110.

Stump, B. W. and S. K. Reamer (1988). Temporal and spatial source effects from near-surface explosions, 10 th Annual AFGLDARPA Seismic Research Symposium, Fallbrook, CA.

Stump, B. W. and R. E. Reinke (1988). Experimental confirmation of superposition from smallscale explosions, Bull. Seism. Soc. Am. 78, 1059-1073.

Stump, B. W. and D. C. Pearson (1995). LANL source geometry quick look report, EES3-95-175, June 9,1995

Vergino, E. S. and R. W. Mensing (1990). Yield estimation using regional $m_{b}(P n)$, Bull. Seism. Soc. Am. 80. 656-674.

Wuster, J. (1993). Discrimination of chemical explosions and earthquakes in central Europe--a case study, Bull. Seism. Soc. Am. 83, 1184-1212. 